\title{
Quality Improvement in Investment Castings Using Genetic Algorithm
}

\author{
Hussam Abbas ${ }^{*}$, Amit Sata** \\ *Mechanical Engineering Department, Faculty of Engineering, Marwadi Education Foundation Group of Institutes, \\ Postgraduate student, Rajkot 360003, Gujarat, India'

\begin{abstract}
** Mechanical Engineering Department, Faculty of Engineering, Marwadi Education Foundation Group of Institutes, Professor, Rajkot 360003, Gujarat, India. (hossmabass998@gmail.com, amit.sata@ marwadieducation.edu.in)

Corresponding Author; Hussam Abbas, Rajkot 360003, Gujarat, India, Tel: +91 9537341577 , hossmabass998@gmail.com
\end{abstract}

Received: 17.05.2021 Accepted: 02.11.2021

\begin{abstract}
Investment casting is well-known for its distinguished characteristics such as manufacturing small industrial components of ferrous as well as nonferrous alloys used in aerospace, automobile, bio-medical, chemical, defense, etc. with closed tolerances at relatively low cost. These industrial components need to be defect free as well as must possess desired mechanical properties. This quality metrics (defect free castings with desired mechanical properties) is mainly driven by process parameters associated with different sub-processes of investment casting including wax pattern making, shell making, dewaxing, melting \& pouring, and chemical composition of alloys. It is always challenging to identify such parameters affecting quality of investment castings. In this work, an application of Genetic Algorithm has been extended to identify critical parameters and their specific set of values affecting quality of investment castings. This technique is found be very useful in performing data analytics.
\end{abstract}

Keywords: Investment Casting, Data Analytics, linear Regression, Genetic Algorithm.

\section{Introduction}

Investment casting is mostly employed to product industrial castings used in aerospace, automobile, biomedical, chemical and defense sectors [16]. It is mainly comprised of various sub-processes including wax pattern making, shell making, dewaxing, and melting \& pouring. Wax patterns are usually prepared by using $30-70 \%$ industrial wax, $20-60 \%$ plastic, and $0-5 \%$ resin. The industrial wax is usually kept in molten state using heater fitted in wax injection machine, and injected into metallic die (usually made of aluminum) to make pattern (replica of casting). These patterns initially cleaned, and then assembled with gating system (sprue, runner as well as gate) to form the tree (assembly of number of wax patterns forming tree like shape). This assembled tree is progressively dipped into ceramic slurry (mixture of zircon flour, binder such as colloidal silica, and some additives) to form coating surrounded to it. The shell (mold) is cured in controlled environmental condition to achieved desired strength. The shell (once cured) is then passed through dewaxing process where wax is ejected (mostly through autoclave machine), and sent for preheating (usually for 30-45 minute at 1000$1100^{\circ} \mathrm{C}$ ) to improve hot strength. Metal/alloy is melted in furnace, and then molten metal/alloys is poured into heated shell. Shell is broken (once it is cooled) to get castings [1][2].

Investment casting mostly faces quality issue related to occurrence of defects including flash (excess metal dropping perpendicularly on the surfaces), misrun (cavities void of liquid metal in the mold), ceramic inclusion (trapping the particles of the ceramic on the surface or subsurface of castings), slag inclusion (dropping off a combination of metal and investment materials on the surface of castings), 
shrinkage (tiny cavities similar to a sponge in the last solidifying portion), sweating (dropping metal irregularly on the surfaces of castings), distortion (regarding the shape in original for castings), and crack (The local discontinuity is formed from concentrated stress through solidification). The castings also possess higher set of mechanical properties such as ultimate tensile strength, yield strength, and elongation [1][2].

The quality metrics mentioned above is highly influenced by process parameters as well as chemical composition of alloys. These parameters are also varied in various sets. It is pressing need to identify such parameters and their specific set of values to achieve desired quality in investment castings. Once these parameters are identified, it becomes relatively easy to control form improving the quality in castings [1][2].

In this work, relatively new approach, genetic algorithm is employed to identify such parameters and their specific set of values from data set collected from an industrial foundry located at authors' home town. It really provided an opportunity to explore genetic algorithm for identifying such parameters, and found it very useful in implementation.

\section{Literature Review}

Various researchers have attempted to explore Genetic Algorithm (GA) for optimization of process parameters for various processes. Patel et al, (2016) applied GA to determine the optimal process parameters. Model has been develop using nonlinear regression to recognize the considerable impact of the process parameters of the squeeze cast method on surface hardness, tensile strength, and roughness. Santos et al, (2003) developed a computational algorithm for the continuous casting method to maximize quality of steel billet. The GA has been integrated with a mathematical model using knowledge base of operational parameters. Anijdan et al, (2006) developed a theoretical model based on GA that was further integrated with artificial neural network to optimize the parameters responsible for the formation of porosity in castings of Al-Si alloys. Ducic et al, (2017) exhibited an application of GA for sand casting process to optimize the geometry of the gating system for maximizing the filling rate. Vijian et al, (2007) developed a mathematical model using multivariate linear regression analyses to formulate the objective functions that can further be used in development of GA for optimizing squeeze casting process parameters to improve mechanical properties of castings. Patel et al, (2016) used three evolution algorithms including Particle Swarm Optimization, Genetic Algorithm, and Multi Objective Particle Swarm Optimization Algorithm using Crowding Distance technique (MOPSO-CD) for improving the variables related to input- output in squeeze casting process. It was observed that these techniques can be implemented for optimization of variables in casting process however GA performs better in comparison with other approaches. Tsoukalas (2008) developed an efficient approach using multivariable linear regression with the GA to reduce the porosity in $\mathrm{Al}$ alloy manufactured using die casting process. The application of GA with multivariable linear regression is found to be very effective for improving the performance of process. Lagdive et al, (2013) used the GA with computer-aided design to generates an intelligent initial design for riser, and found it very useful in getting improved results.

It was revealed that several researchers have explored the application of GA in optimizing the overall performance of casting process with relatively small number of parameters. However, an application of GA for investment casting process where relatively large number of parameters are varied in wide set is not fully explored. As GA mainly relies on information related to input data as well as output, large set of input was collected from an industrial investment casting foundry located in Rajkot (India). Detailed methodology adopted for identification of critical parameters and their specific set of values affecting quality of investment casting is discussed next followed by results and discussion on it.

\section{Methodology}

Methodology adopted for identification of critical parameters and specific set of values affecting quality of investment casting is shown in Fig. 1.

Pre-processing section mainly focused on collection of data from industrial foundry, and development of relevant model using linear regression. The developed model will further be utilized for applying GA. Processing performs analysis using GA that further includes different steps such as initialization as well as selection of population, followed by reproduction and termination of population for converging the solution. Post-processing provides results related to critical parameters and their specific set of values to achieve desired quality through model developed by GA. Detailed explanation of each step is given next. 


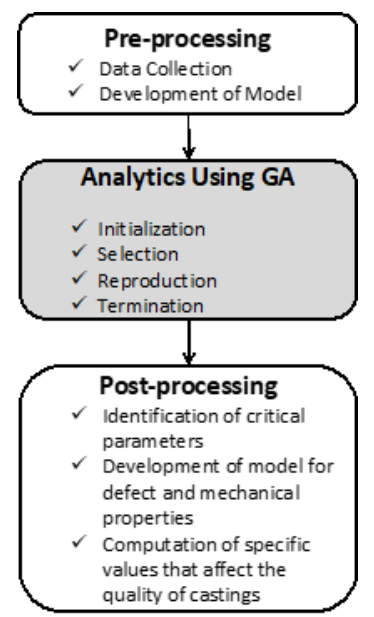

Fig. 1. Methodology adopted

\section{Pre-processing}

Input data related to process parameters as well as chemical composition and quality metrics (occurrence of defects as well as mechanical properties) was collected from an industrial investment casting foundry located at Rajkot (India). In total, 15 parameters related to process parameters; 9 parameters related to chemical composition; five defects such as slag inclusion, shrinkage, misrun, flash and ceramic inclusion; three mechanical properties (UTS, YS and ELOG) were collected, and stored in the form of spreadsheet. Occurrence of defects was entered " 1 " while non-occurrence of defects as "0". However, data related to shell weight before as well as after dewaxing was further merged together to get its absolute value (initial weight was subtracted from its final weight). The input data collected was related to nearly 360 heats (cycle of melting and pouring) of industrial casting (Fig.2) that has major application in automobile sector. Input parameters along with minimum and maximum values of each parameters as well as values of mechanical properties are shown in Table 1.

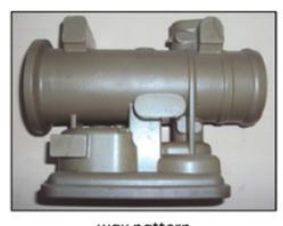

waxpattern
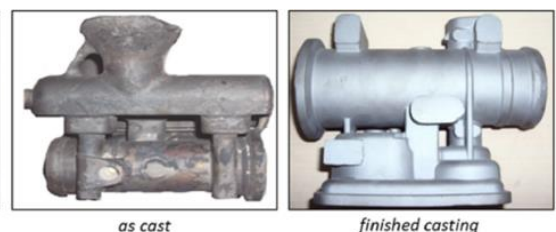

Fig. 2. Industrial castings

These parameters are further utilized for development of model that will further be utilized in performing analytics using GA. Model was developed using fundamentals of multiple linear regression shown in equation 1 .

$y_{i}=\beta_{0}+\beta_{1} x_{1 i}+\beta_{2} x_{2 i}+\cdots+\beta_{p} x_{p i}+e_{i} \ldots$

where: $\beta_{0}$ : is the constant, $P$ : number of variables and each variable has its $\beta$ coefficient.

\section{Analytics Using GA}

Genetic Algorithm is a computational technique that provides exact or approximate solutions especially for optimization as well as search related problems, and categorized as one of the evolutionary algorithms [3]. Detailed discussion on methodology to optimize the problem using GA is available in various literatures [3] [6][7][8][9][12]. GA is usually employed to evolve the expressions (equations) for optimizing the process where number of variables are (similar to number of variables in investment casting process) relatively large (say, 10,20 50 or more) [3]. The GA usually adopts steps initiate for an initial population from input data; select most possible solutions through evaluation using

Table 1. Details of input and output parameters

\begin{tabular}{|l|c|c|c|c|c|}
\hline \multicolumn{1}{|c|}{ Input/Output } & Notation & Units & Minimum & Maximum & Mean \\
\hline Input - Process Parameters & & & & & \\
\hline Metal Preparation Time & $x_{1}$ & $\min$ & 55 & 135 & 75.78 \\
\hline Tapping Temperature & $x_{2}$ & ${ }^{0} \mathrm{C}$ & 1550 & 1580 & 1559.60 \\
\hline Injection Time & $x_{3}$ & $\mathrm{sec}$ & 0.83 & 10.4 & 8.83 \\
\hline Press Room Temperature & $x_{4}$ & ${ }^{\circ} \mathrm{C}$ & 18 & 21.67 & 18.60 \\
\hline Press Room Humidity & $x_{5}$ & $\%$ & 69.75 & 90 & 78.43 \\
\hline Duration of Process & $x_{6}$ & In days & 2 & 7 & 4.32 \\
\hline $\begin{array}{l}\text { Weight of Shell (difference between weight of } \\
\text { shell after dewaxing and before dewaxing) }\end{array}$ & $x_{7}$ & $\mathrm{~kg}$ & 1.34 & 2.64 & 1.89 \\
\hline Slurry Viscosity - Primary & $x_{8}$ & $\mathrm{sec}$ & 20.38 & 23.59 & 21.54 \\
\hline Slurry pH - Primary & $x_{9}$ & -- & 9.0 & 9.50 & 9.35 \\
\hline Temperature of Coating Room - Primary & $x_{10}$ & ${ }^{0} \mathrm{C}$ & 19.25 & 24.33 & 21.90 \\
\hline Humidity of Coating Room - Primary & $x_{11}$ & $\%$ & 9.50 & 79.7 & 68.72 \\
\hline
\end{tabular}




\begin{tabular}{|l|c|c|c|c|c|}
\hline Slurry Viscosity - Secondary & $x_{12}$ & sec & 10.32 & 11.06 & 10.56 \\
\hline Temperature of Coating Room - Secondary & $x_{13}$ & ${ }^{0} \mathrm{C}$ & 20.5 & 26.4 & 23.41 \\
\hline Humidity of Coating Room - Secondary & $x_{14}$ & $\%$ & 64.75 & 85.40 & 75.20 \\
\hline Input - Chemical Composition & & & & & \\
\hline Nickel-Extra & $x_{15}$ & $\mathbf{\%}$ & 0.001 & 0.66 & 0.08 \\
\hline Manganese & $x_{16}$ & $\mathbf{\%}$ & 0.751 & 1.26 & 0.96 \\
\hline Carbon & $x_{17}$ & $\mathbf{\%}$ & 0.04 & 0.07 & 0.05 \\
\hline Silicon & $x_{18}$ & $\mathbf{\%}$ & 1.12 & 1.37 & 1.23 \\
\hline Phosphorous & $x_{19}$ & $\mathbf{\%}$ & 0.03 & 0.04 & 0.037 \\
\hline Sulphur & $x_{20}$ & $\mathbf{\%}$ & 0.01 & 0.03 & 0.01 \\
\hline Nickel & $x_{21}$ & $\mathbf{\%}$ & 8.01 & 8.46 & 8.18 \\
\hline Chromium & $x_{22}$ & $\mathbf{\%}$ & 18.02 & 18.54 & 18.27 \\
\hline Molybdenum & $x_{23}$ & $\mathbf{\%}$ & 0.11 & 0.31 & 0.23 \\
\hline Output - Mechanical Properties & & & & & \\
\hline Ultimate Tensile Strength & $y_{1}$ & MPa & 506.10 & 588.40 & 556.65 \\
\hline Yield Strength & $y_{2}$ & MPa & 220.50 & 305.10 & 282.31 \\
\hline Elongation & $y_{3}$ & $\%$ & 50.20 & 60.40 & 55.50 \\
\hline Output - Defects & & & & & \\
\hline Ceramic Inclusion & $y_{4}$ & -- & -- & -- & -- \\
\hline Flash & $y_{5}$ & -- & -- & -- & -- \\
\hline Misrun & $y_{6}$ & -- & -- & -- & -- \\
\hline Shrinkage & $y_{7}$ & -- & -- & -- & -- \\
\hline Slag Inclusion & $y_{8}$ & -- & -- & -- & -- \\
\hline
\end{tabular}

fitness function; reproduce the results; terminate the process based on desired criteria to get optimized results. Various steps to be followed for analytics using GA is shown in Fig. 3.

\subsection{Initialization}

This is the first step for optimization of process using GA, and it generates (randomly) many individual solutions from input data. This usually generates all possible solutions, and evaluation criteria needs to be provided for selecting most optimum solution suitable for relevant process. As discussed earlier, data collected from an industrial investment casting foundry is stored in the form of spreadsheet, and used for initialization of solution. This step has generated all possible solutions using input data, and will forward the possible solutions for selection (shortlist).

\subsection{Selection}

This is one of the very critical steps in optimizing process using GA. This step selects few solutions among all possible solutions (generated in the initialization step). The selection is carried out using fitness-based process using fitness function that will select appropriate fitter solution for next step. Selection of appropriate method for selecting possible solution among all possible solutions is very critical as inappropriate selection may take very long time for getting solution or solution may not be converged for final solution. The selected solutions will further used in reproduction step that will generate second generation (mutation) of possible solutions from it.

\subsubsection{Reproduction}

This step will generate second generation of populations from shortlisted solutions from previous step. This is achieved by selecting a pair (usually known as parent) of solutions from the selected possible solutions. This is followed by crossover and mutation process among parent for creating next level of solution (known as child). This next level of solution (child) usually have many characteristics from its parent. The process of reproduction continues till new set of possible solutions is generated. This in turn leads into generation of entirely new set of solutions that was achieved at the end of initialization step as fitness function selected the best possible solutions from the results of previous steps. The reproduction process is continuous process, and it has to be terminated to achieve desired solution that fulfils predefined criteria.

\subsubsection{Termination}

The reproduction was continued till either of following termination criteria was achieved. Most common termination 
criterion used in termination of reproduction step is either of followings [3]:

- Number of generations (i.e. iterations),

- Time taken for achieving solution,

- Highest fitness achieved beyond which improvement in results is not possible,

- Manual inspection of results for observing improvement in results.

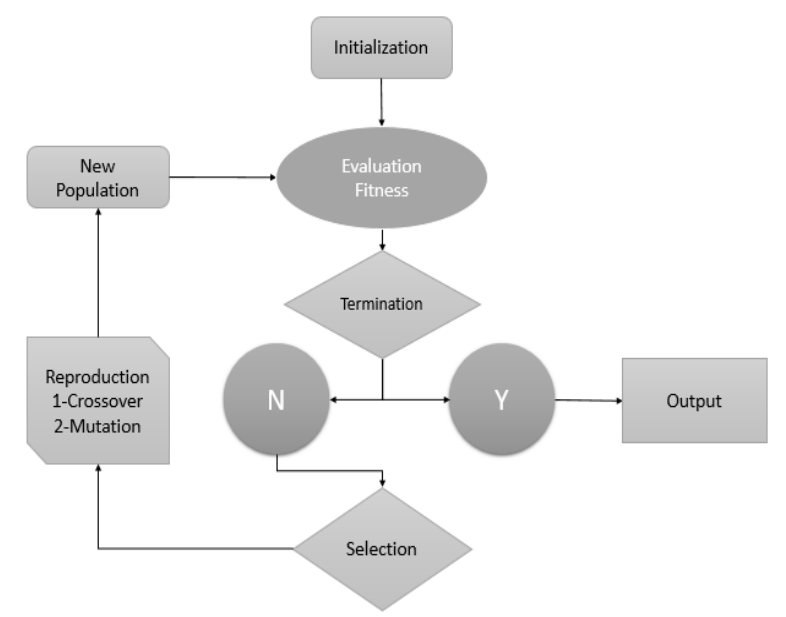

Fig. 3. Overview of analytics carried out using GA

As discussed earlier, input data related to 358 heats comprising 15 process parameters, 9 chemical composition

Table 2. Values of the Coefficients - Mechanical Properties and Defects

\begin{tabular}{|c|c|c|c|c|c|c|c|c|}
\hline & $y_{1}$ & $y_{2}$ & $y_{3}$ & $y_{4}$ & $y_{5}$ & $y_{6}$ & $y_{7}$ & $y_{8}$ \\
\hline$\beta_{0}$ & 0.6323 & 0.8502 & 0.9733 & 0.32 & -0.0718 & 0.0769 & 0.8426 & 0.8501 \\
\hline$\beta_{1}$ & -0.056 & -0.053 & 0.069 & -0.01 & 0.082 & 0.041 & -0.2 & -0.18 \\
\hline$\beta_{2}$ & -0.045 & -0.025 & -0.29 & 0.16 & 0.054 & 0.039 & -0.19 & -0.18 \\
\hline$\beta_{3}$ & -0.0022 & -0.032 & -0.15 & -0.018 & 0.12 & -0.046 & -0.019 & 0.0054 \\
\hline$\beta_{4}$ & 0.064 & 0.056 & 0.052 & 0.037 & 0.12 & 0.049 & -0.21 & -0.33 \\
\hline$\beta_{5}$ & 0.11 & 0.037 & 0.051 & -0.13 & -0.0049 & 0.041 & -0.27 & -0.39 \\
\hline$\beta_{6}$ & 0.17 & -012 & 0.08 & 0.031 & -0.031 & -0.039 & 0.34 & 0.25 \\
\hline$\beta_{7}$ & -0.34 & 0.064 & -0.36 & -0.1 & -0.043 & 0.073 & -0.47 & -0.49 \\
\hline$\beta_{8}$ & -0.15 & -0.027 & 0.024 & 0.032 & 0.11 & 0.22 & 0.04 & -0.032 \\
\hline$\beta_{9}$ & -0.034 & 0.027 & -0.046 & 0.06 & 0.1 & 0.078 & -0.095 & -0.14 \\
\hline$\beta_{10}$ & -0.069 & 0.077 & 0.044 & 0.39 & -0.086 & 0.35 & 0.15 & 0.1 \\
\hline$\beta_{11}$ & 0.11 & -0.12 & 0.092 & -0.12 & 0.032 & -0.14 & 0.1 & 0.13 \\
\hline$\beta_{12}$ & 0.04 & -0.0013 & 0.13 & -0.083 & -0.046 & -0.17 & 0.029 & 0.07 \\
\hline$\beta_{13}$ & 0.036 & -0.066 & 0.068 & 0.018 & -0.17 & -0.15 & -0.013 & -0.066 \\
\hline$\beta_{14}$ & -0.007 & 0.079 & 0.0032 & 0.18 & 0.12 & +0.19 & 0.15 & 0.12 \\
\hline$\beta_{15}$ & -0.28 & 0.11 & -0.31 & 0.11 & 0.096 & -0.16 & -0.25 & -0.13 \\
\hline$\beta_{16}$ & 0.1 & -0.012 & -0.098 & -0.17 & -0.062 & -0.055 & -0.17 & 0.0022 \\
\hline$\beta_{17}$ & 0.12 & 0.069 & 0.11 & -0.14 & 0.19 & -0.035 & -0.026 & -0.065 \\
\hline$\beta_{18}$ & -0.082 & -0.066 & 0.11 & 0.065 & -0.19 & -0.11 & -0.059 & -0.043 \\
\hline$\beta_{19}$ & -0.13 & -0.2 & -0.28 & 0.14 & 0.16 & -0.032 & 0.2 & 0.071 \\
\hline$\beta_{20}$ & -0.033 & 0.015 & -0.44 & -0.17 & -0.13 & -0.024 & -0.0086 & 0.16 \\
\hline
\end{tabular}

of alloy, five defects and three mechanical properties was used to as an input to identify critical parameters and their specific set of values to achieve desired quality in investment castings using GA. This data was used to generate multiple linear equations that will be used in selection step for analytics using GA. Generalized equation was generated (equation 2), and their relevant coefficients for data related to defects and mechanical properties are shown in Table 2.

$y_{d i}=\beta_{0}+\beta_{1} x_{1}+\beta_{2} x_{2}+\cdots+\beta_{23} x_{23} \cdots \cdots$

where $y_{i}=$ outputs; $y_{1}=$ Ultimate Tensile Strength; $y_{2}=$ Yield Strength; $y_{3}=$ Elongation, $y_{4}=$ Slag Inclusion; $y_{5}=$ Shrinkage, $y_{6}=$ Misrun; $y_{7}=$ Flash; $y_{8}=$ Ceramic Inclusion; $\beta_{0}=$ Intercept; $x_{1,2,3 \ldots 23}=$ Process parameters and chemical compositions; $\beta_{1,2,3 \ldots 23}=$ Relevant co-efficient of process parameters and chemical compositions

In total, 358 solutions were possible for optimization after passing through selection step. These solutions were further passed through fitness function. Two different sets of fitness function were employed each for separate set of outputs (mechanical properties and defects). Fitness function related to defects were modeled in such way that yield in minimization of defects while for mechanical properties that yield in maximization. 


\begin{tabular}{|c|c|c|c|c|c|c|c|c|}
\hline$\beta_{21}$ & 0.038 & 0.0017 & 0.17 & -0.11 & 0.098 & 0.033 & -0.12 & -0.21 \\
\hline$\beta_{22}$ & -0.25 & -0.051 & -0.096 & -0.014 & -0.051 & -0.17 & -0.048 & -0.016 \\
\hline$\beta_{23}$ & 0.1 & 0.037 & -0.093 & -0.24 & 0.079 & -0.041 & -0.13 & -0.15 \\
\hline
\end{tabular}

The fitness function was employed to evaluate each solution. In total, 150 solutions were further selected for reproduction. The reproduction was further iterated for 100 generations, and terminated as it was not showing further improvements in results. The solutions using GA was coded and executed on the platform of python.

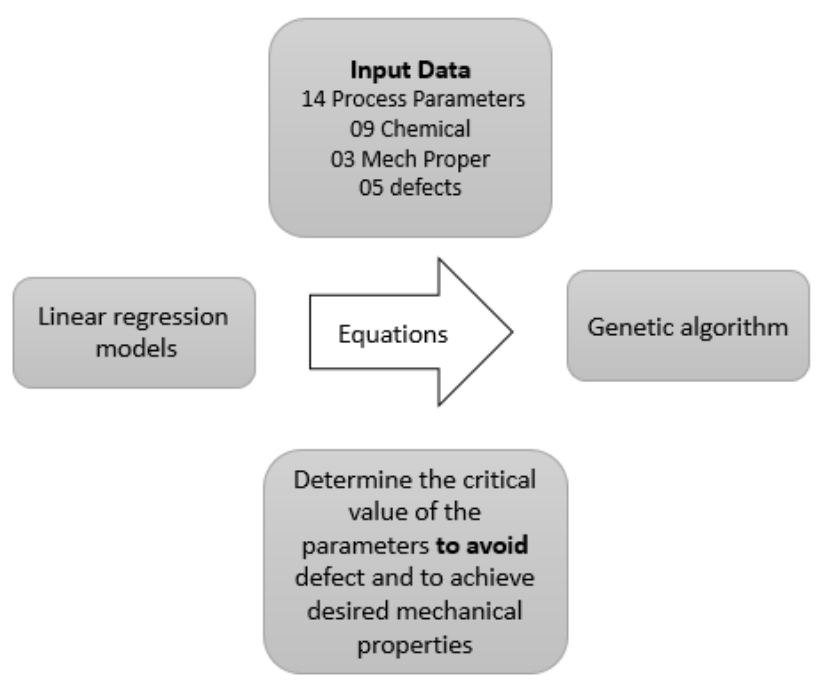

Fig. 4. Computation of critical parameters

\section{Results}

The input data related to process parameters, as well as chemical composition used to identify critical parameters and their specific set of value affecting the quality (minimizing the occurrence of defects and maximizing the mechanical properties) of investment castings using GA. The parameters and their specific set of values to achieve desired quality of investment castings are shown in table 3.

\section{Discussion}

The Genetic Algorithm based model has been successfully developed and found to be useful for identifying the specific set of values affecting the quality of investment castings. The models can be easily embedded with cloud based technology, and utilized by user. This model do not need a high level of domain knowledge or computation tools (as for simulation software). The process data can be collected from an industrial foundry and stored in spreadsheet, which can be formed the main input. The model was tested on real-life data obtained from an industrial investment casting foundry, and was found to be easy to use by foundry engineers, without any training or customizing. The parameters identified for achieving desired quality are considered to be in line with previous work. $\mathrm{pH}$ values of primary slurry and humidity of primary coating room drives the quality of the ceramic shell; affects heat transfer rate during solidification of alloy, and alter the mechanical properties. Similarly, weight of shell drives the thickness of coating. Thin shell improves the heat transfer between shell and alloy, and affects the mechanical properties of alloy. However, difficult to establish the complete correlation between parameters and quality of investment casting, and more research may be needed in this direction.

Table 3. Specific Set of Values Affecting Quality of Casting

\begin{tabular}{|l|c|c|c|c|c|c|c|c|c|}
\hline \multirow{2}{*}{\multicolumn{1}{c|}{ Parameter }} & \multirow{2}{*}{ Notation } & \multicolumn{3}{|c|}{ Mechanical Properties } & \multicolumn{5}{c|}{ Defects } \\
\cline { 3 - 11 } & & $y_{1}$ & $y_{2}$ & $y_{3}$ & $y_{4}$ & $y_{5}$ & $y_{6}$ & $y_{7}$ & $y_{8}$ \\
\hline Metal Preparation Time & $x_{1}$ & 69 & 75 & 70 & 65 & 66 & 70 & 73 & 115 \\
\hline Tapping Temperature & $x_{2}$ & 1558 & 1553 & 1557 & 1561 & 1558 & 1563 & 1568 & 1562 \\
\hline Injection Time & $x_{3}$ & 9.4 & 9.7 & 5.63 & 10.1 & 9.7 & 9.4 & 9.2 & 7.2 \\
\hline Press Room Temperature & $x_{4}$ & 18 & 19.9 & 21.7 & 18 & 18 & 19.32 & 18 & 18 \\
\hline Press Room Humidity & $x_{5}$ & 90 & 69.8 & 75.6 & 84.9 & 77 & 73.2 & 84.2 & 84.1 \\
\hline Duration of Process & $x_{6}$ & 7 & 4 & 4 & 3 & 4 & 4 & 3 & 4 \\
\hline
\end{tabular}




\begin{tabular}{|l|c|c|c|c|c|c|c|c|c|}
\hline $\begin{array}{l}\text { Weight of Shell (difference } \\
\text { between weight of shell after } \\
\text { dewaxing and before dewaxing) }\end{array}$ & $x_{7}$ & 1.5 & 1.5 & 1.1 & 1.5 & 1.3 & 1.4 & 1.5 & 1.4 \\
\hline Slurry Viscosity - Primary & $x_{8}$ & 21 & 21.7 & 22.4 & 20.5 & 20.4 & 20.6 & 21.7 & 21.7 \\
\hline Slurry pH - Primary & $x_{9}$ & 9.3 & 9.5 & 9.3 & 9 & 9.5 & 9.25 & 9.5 & 9.5 \\
\hline $\begin{array}{l}\text { Temperature of Coating Room - } \\
\text { Primary }\end{array}$ & $x_{10}$ & 21.6 & 21.8 & 23.7 & 21.2 & 23 & 23.1 & 22.2 & 21.7 \\
\hline $\begin{array}{l}\text { Humidity of Coating Room - } \\
\text { Primary }\end{array}$ & $x_{11}$ & 71.3 & 9.5 & 79.4 & 73.4 & 67.1 & 69.9 & 9.5 & 9.5 \\
\hline Slurry Viscosity - Secondary & $x_{12}$ & 11.1 & 10.6 & 11.1 & 10.4 & 10.5 & 10.4 & 10.5 & 10.5 \\
\hline $\begin{array}{l}\text { Temperature of Coating Room - } \\
\text { Secondary }\end{array}$ & $x_{13}$ & 21.8 & 22.8 & 21.8 & 23 & 26.4 & 25.9 & 26.4 & 25 \\
\hline $\begin{array}{l}\text { Humidity of Coating Room - } \\
\text { Secondary }\end{array}$ & $x_{14}$ & 82 & 20.4 & 82 & 73.6 & 76.5 & 79.6 & 76.4 & 69.5 \\
\hline Nickel-Extra & $x_{15}$ & 0.05 & 0.24 & 0.09 & 0.001 & 0.07 & 0.1 & 0.7 & 0.1 \\
\hline Manganese & $x_{16}$ & 0.82 & 1.27 & 0.85 & 0.85 & 1.07 & 0.93 & 1.03 & 1.02 \\
\hline Carbon & $x_{17}$ & 0.06 & 0.04 & 0.06 & 0.05 & 0.05 & 0.06 & 0.05 & 0.05 \\
\hline Silicon & $x_{18}$ & 1.23 & 1.32 & 1.2 & 1.25 & 1.25 & 1.28 & 1.2 & 1.2 \\
\hline Phosphorous & $x_{19}$ & 0.03 & 0.03 & 0.03 & 0.037 & 0.037 & 0.037 & 0.038 & 0.039 \\
\hline Sulphur & $x_{20}$ & 0.01 & 0.01 & 0.01 & 0.008 & 0.008 & 0.01 & 0.008 & 0.009 \\
\hline Nickel & $x_{21}$ & 8.01 & 8.06 & 8.27 & 8.17 & 8.13 & 8.19 & 8.20 & 8.26 \\
\hline Chromium & $x_{22}$ & 18.14 & 18.14 & 18.25 & 18.096 & 18.28 & 18.05 & 18.36 & 18.48 \\
\hline Molybdenum & $x_{23}$ & 0.24 & 0.20 & 0.23 & 0.25 & 0.21 & 0.26 & 0.24 & 0.28 \\
\hline
\end{tabular}

\section{References}

[1] Sata, A., \& Ravi, B. (2019). Foundry data analytics to identify critical parameters affecting quality of investment castings. ASCE-ASME Journal of Risk and Uncertainty in Engineering Systems, Part B: Mechanical Engineering. 5(1): 011010.

[2] Sata, A., \& Ravi, B. (2017). Bayesian inference-based investment-casting defect analysis system for industrial application. The International Journal of Advanced Manufacturing Technology, 90(9), 33013315 .

[3] Kumar, M., Husain, M., Upreti, N., \& Gupta, D. (2010). Genetic algorithm: Review and application. International Journal of Information Technology and Knowledge Management. Volume 2, No. 2, pp. 451454.

[4] Tranmer, M., \& Elliot, M. (2008). Multiple linear regression. The Cathie Marsh Centre for Census and Survey Research (CCSR), 5(5), 1-5.
[5] Yen, Y. S., Chan, Y. K., Chao, H. C., \& Park, J. H. (2008). A genetic algorithm for energy-efficient based multicast routing on MANETs. Computer Communications, 31(10), 2632-2641.

[6] Manjunath Patel, G. C., Krishna, P., \& Parappagoudar, M. B. (2016). Modelling and multiobjective optimization of squeeze casting process using regression analysis and genetic algorithm. Australian Journal of Mechanical Engineering, 14(3), 182-198.

[7] Santos, C. A., Spim, J. A., \& Garcia, A. (2003). Mathematical modeling and optimization strategies (genetic algorithm and knowledge base) applied to the continuous casting of steel. Engineering applications of artificial intelligence, 16(5-6), 511527.

[8] Anijdan, S. M., Bahrami, A., Hosseini, H. M., \& Shafyei, A. (2006). Using genetic algorithm and artificial neural network analyses to design an $\mathrm{Al}-\mathrm{Si}$ casting alloy of minimum porosity. Materials \& design, 27(7), 605-609. 
[9] Dučić, N., Ćojbašić, Ž., Manasijević, S., Radiša, R., Slavković, R., \& Milićević, I. (2017). Optimization of the gating system for sand casting using genetic algorithm. International Journal of Metalcasting, 11(2), 255-265.

[10] Vijian, P., \& Arunachalam, V. P. (2007). Modelling and multi objective optimization of LM24 aluminium alloy squeeze cast process parameters using genetic algorithm. Journal of materials processing technology, 186(1-3), 82-86.

[11] Patel, G. C. M., Krishna, P., Vundavilli, P. R., \& Parappagoudar, M. B. (2016). Multi-objective optimization of squeeze casting process using genetic algorithm and particle swarm optimization. Archives of Foundry Engineering, 16. International Journal of Swarm Intelligence Research (IJSIR), 7.1: 55-74.

[12] Tsoukalas, V. D. (2008). Optimization of porosity formation in $\mathrm{AlSi} 9 \mathrm{Cu} 3$ pressure die castings using genetic algorithm analysis. Materials \& Design, 29(10), 2027-2033.
[13] Lagdive, P. B., \& Inamdar, K. H. (2013). Optimization of riser in casting using genetic algorithm. International Archive of Applied Sciences and Technology, 4(2), 21-26.

[14] Santos, C. A., Cheung, N., Garcia, A., \& Spim, J. A. (2005). Application of a solidification mathematical model and a genetic algorithm in the optimization of strand thermal profile along the continuous casting of steel. Materials and Manufacturing Processes, 20(3), 421-434.

[15] GC, M. P., Krishna, P., Parappagoudar, M. B., \& Vundavilli, P. R. (2016). Multi-objective optimization of squeeze casting process using evolutionary algorithms. International Journal of Swarm Intelligence Research (IJSIR), 7(1), 55-74.

[16] Pattnaik, S., Karunakar, D. B., \& Jha, P. K. (2012). Developments in investment casting process-a review. Journal of Materials Processing Technology, 212(11), 2332-2348. 